\title{
The Analysis of Role of Language in Picture Books on Children's Art Education
}

\author{
Cong PENG ${ }^{1, a,{ }^{*}}$ \\ ${ }^{1}$ Linyi University, Feixian, Shandong, China \\ alydxmfl@126.com
}

Keywords: Picture books, Children's aesthetic education, Image, Composition, Children's aesthetic ability.

\begin{abstract}
The picture, that means aesthetic language, plays a very important role in the process of children's reading, we can absorb aesthetic language from good picture books, and apply it into the process of children's artistic education. Here I will pick up several classic cases, analyze it, and state it from two aspects: the aesthetic language in picture books and the actual application of picture books in children's artistic education.
\end{abstract}

\section{Introduction}

The picture book is a combination of first-class picture and first-class words, is a kind of good educational resources, and has important practical value for the mental development of children. A good picture book can help illiterate child "read". The picture book tells the story mainly through pictures, children can understand the story through observing pictures during their "reading". So, the picture book can help children read the pictures much more deeply, is good medium for training children's power of observations and understandings. Besides, the format of picture book is appropriate and special, the cover, the title page, the contents and back cover, all of them form an almost perfect whole. Because of the emotion the painter has invested, the paintings of picture book are very beautiful. So children will be affected by the art of painting through reading the picture book, and their temperament, intrinsic quality and personality quality will also be cultivated. The popularity of picture book lies not only in the mental shock the story of it has on children, but also in the emotion cultivation the story itself has contained.

"Using picture book in teaching actually means to dialog with children equally." [1]Good picture book can cultivate children's aesthetic ability and their ability of beauty emotionally and visually, children may create beauty through the help of picture book. So I think the artistic education of children can start from good picture book.

\section{The Aesthetic Language in Picture Book}

The picture, that means aesthetic language, plays a very important role in the process of children's reading [2]. I think, the aesthetic language in picture book can be analyzed in three aspects, color, image and composition.

\section{Color------Rich and Vibrant}

Rich and vibrant color in picture book will enable children to gain the most direct feelings through their reading, it plays a key role in cultivating children's aesthetical conception ability, and enriching their aesthetic emotion. Color also is the important 
factor in conveying emotion of the picture book, and creating the atmosphere of image. The bright and vibrant color in picture book can provide rich aesthetic carrier for children, help them develop integral mental structure and specific aesthetic emotion, enrich their artistic sensibility.

Take the case of the picture book created by the great Dutch children's writer and painter, Hendrik Magdalenus Bruna, Miffy. The aesthetic language and lines of it are rather simple, it adopts only several simple color blocks, and conveys simple and direct message to children. The background color of Miffy is rather daintily, red, yellow, blue and green, all are solid colors; but if children are leaded to observe the picture carefully, they will be surprised to find that all these simple background colors conveys different message to readers: red means at home, green represents on the road or hill by the sea, blue means sea or sky, yellow means on the bank or sands. Such colors full of theme, are easy to catch the eye of children, like a beautiful song, flows into the heart of children slowly. Besides enable children to feel the wonder of the world, but also enable them to understand the hidden meaning of different colors. The bright and vibrant colors make children accept the story easily during the reading [3].

\section{Image---Vivid}

The image of characters is essential in picture book, the character shaping has strong artistic expression. The story in different picture books are different, so the images set to paper by the painters are different, the clarity of image, the integrity of the shape, the simplicity of the lines and the definition of the intention, all these factors will influence children's understanding in contents of picture book. Vivid images will nourish children's mind subtly during their process of reading, and give them enjoyment of beauty.

For instance, the picture book created by Irish writer Sam McBratney, -- Guess How Much I Love You. Through the vivid body language, changing images of the adult rabbit and baby rabbit, it conveys the message of love. The baby rabbit is going to bed, in the picture, there have no beautiful quilt, no children's bed, no beautiful pajamas, all there have is only a cluster of grass. Yet justt the two rabbits, created through sketching lines and enjoyable painting, the humorous and vivid image of them are funny to children, and give deep impression on their mind.

Thus can be seen that, different characteristics of the image, vivid and interesting storyline can touch children's hearts through the image of the character in the picture book, the aesthetic emotion language expressed by the image is rich and direct. Good picture book will enable children to obtain more and more message conveyed by the picture through repeating reading, they can catch the details of the picture, and fill in the gaps in picture through their own imagination, use their imagination to enrich the storyline, their aesthetic ability will also be promoted gradually.

\section{Composition---Changeable}

The unique composition in picture book can give children fresh, exciting visual impact and sweet visual perceptions [4]. As for picture books, the composition has enormous possibility of change, the unique design of every piece of picture is also responded to the structure and ideas of the whole book.

For instance, the picture book created by Canadian writer, Phoebe Gilman, Something from Nothing, is filled with unique composition. The writer has painted an old but friendly Jewish community as the main part of the picture in the upper part of the page, around the picture, it is decorated with such wooden frame like beams, floors and 
windows. In the lower part of the page, it's a different small world, which shows the life of little mouse. Such kind of compositions, that the upper part is parallel with the lower part, will attract children to observe the picture carefully and find out the interesting details in pictures, enable them to enjoy reading from unique compositions, and obtain special aesthetic feelings. Children already have certain perceptions on the compositions of picture, picture books with better compositions can attract children's attention better through the aesthetic language it conveyed, it also will enable children to be nurtured in the beauty through reading, and make good foundations for their future artistic creations.

Good picture books should be organic combination of the color, image and compositions, during teaching activities, teachers should be good at using the aesthetic language in picture books, lead children to find out beauty, to experience beauty, to appreciate beauty, and to communicate beauty, lead children to apply the way they have learned to reveal beauty into activities like painting and making books, combine reading with arts organically.

\section{The Practical Use of Picture Book in Children's Artistic Education}

Japanese researcher Songjuzhi holds the idea that the language world from ears and language world from eyes merged into one in children's mind. Actually, the world appeared in children's mind is the picture book. It is the clue, the entrance, I call it the picture-book experiences, while just through such kind of picture-book experiences, children enter into the language world. Then, the question is: how to apply the picture book into our practical aesthetic education?

Adapt the story according to the original style. Through painting, students get the sensation of being, understand the unspoken setbacks, catastrophes, parting and death, get into inner world of themselves, the picture book becomes their window for getting to know themselves and getting to know the world. Through the picture book, children can release their emotions and satisfy the need of mental development.

Come up with new stories according to the original style and storyline of the picture book. We can learn such drawing skills in the picture book as compositions, colors, and the way to tell story, get to know the potential rhythms in picture book, master the way to reveal details, and encourage students to try to come up with new story that is based on their own life, and combined with their own ideas, in the way that they are good at, furthermore students can learn to search for subjects and write script by themselves and make picture books according to the storyline.

Expand children's understanding and studying on multi-culture, get to know the diversity of artistic style. Good picture book comes from countries around the world, different country has different culture, when such difference shows up in children's book, different techniques and styles come into birth; besides, the design of scene, the image of character, the use of painting language and excellent association, creations, humorous techniques of expression, and rich humanistic spirit, all of these in the picture book, contains plenty of excellent artistic resources worth references to. Excavating artistic knowledge from good children's picture book and apply it into artistic appreciation teaching, will motivate much more students' interest in studying, and enable them to understand the artistic style much better.

Lead children to experience and try diverse drawing techniques in picture book. Children's picture book has plenty of expressive skills, such as prints, watercolor, pencils, oil paintings and acrylic paintings and so forth. It is exactly such diversity 
makes the picture book has beautiful appearance, an enable picture book to become the resource treasury of artistic teaching [5].

Lead students to observe the details in picture book. For instance, a full book consists of cover, end paper, pages and the back cover, each part has its corresponding role. The age and ability of children decide that they can't tell a complete story as professionally as artists, whether the end paper exist or not is not important for them, what matters is that they can express their own consciousness and thoughts through picture books during their process of creating.

\section{Summary}

"The value of art must be learned by intuition. Such kind of intuition is not born. Artistic intuition can only be the outcome of long-term education. Our eyes cannot see anything when we were born, only through training can we get to understand what we saw." American artist Ben Shah once said such words in Notes on A Painting. Appreciating famous paintings purely is difficult for children, inappropriate way of leading and educating will backfire. Deeply feeling the role of artistic education played in promoting children's artistic quality, I suggest we can take the way of edifying teaching through select good picture books according to children's hobbies. To enjoy is better than just to know, while to love is better than to enjoy. Teachers should be not only good at finding out students' hobbies, but also should catch the opportunity in time to organize teaching, transfer students' passion on reading picture books into motivations to learn art, then integrate children's aesthetics, literature and psychology into each other organically during the practical teaching,.

\section{Reference}

[1] Songjuzhi, My Views on Picture Books [M] (Ji Ying trans.) Changsha: Hunan Children's Publishing House, 1997.

[2] Ji Ying, As A Kind of Art-Picture Books [J]. Research on Children's Book, 1990.

[3] Wang Lin, Yu Zhiying, Appreciation of Picture Books and Creative Teaching [J]. Hebei Education Publishing House, 2010.

[4] Kang Changyun, Research on Reading Process of Children's Picture Books [M].Educational Science Publishing House, 2007.

[5] Lin Meiqin, What's Cool about Picture Books [M]. Xinjiang Juvenile Publishing House, 2011. 